\begin{tabular}{|c|l|}
\hline Title & A mmonolysis of HTiNb05-n-Propylamine Intercal ation Compound \\
\hline Author(s) & Masubuchi, Y uji; Y amakami, Chihiro; Motohashi, Teruki; Kikkawa, Shinichi \\
\hline Citation & $\begin{array}{l}\text { Chemistry Letters, 40(11), 1238-1239 } \\
\text { https://doi.org/10.1246/1.2011.1238 }\end{array}$ \\
\hline Issue Date & 2011-11 \\
\hline Doc URL & http://hdl.handle.net/2115/50383 \\
\hline Type & article (author version) \\
\hline File Information & CL40-11_1238-1239.pdf \\
\hline
\end{tabular}

Instructions for use 


\title{
Ammonolysis of $\mathrm{HTiNbO}_{5}$ (n-propyl amine) Intercalation Compound
}

\author{
Yuji Masubuchi,* Chihiro Yamakami, Teruki Motohashi and Shinichi Kikkawa \\ ${ }^{1}$ Faculty of Engineering, Hokkaido University, N13 W8, Kita-ku, Sapporo Hokkaido 060-8628, Japan
}

(Received <Month><Date>, <Year>; CL-<No>; E-mail: <yuji-mas@eng.hokudai.ac.jp>)

The ammonolysis reaction to form $(\mathrm{Ti}, \mathrm{Nb}) \mathrm{N}$ was enhanced by the use of the $\mathrm{HTiNbO}_{5}$ (n-propyl amine) intercalation compound as a starting material compared with that for a simple mixture of $\mathrm{TiO}_{2}$ and $\mathrm{Nb}_{2} \mathrm{O}_{5}$. The ammonolysis product formed at $1200{ }^{\circ} \mathrm{C}$ was a superconductor $\left(\mathrm{T}_{\mathrm{c}}=15 \mathrm{~K}\right)$ with a rock-salt type crystal structure having many structural defects along the stacking direction of the intercalation compound.

Oxynitrides have attracted interest for application as white light emitting diode (LED) phosphors, ${ }^{1,2}$ possible leadfree dielectric materials, ${ }^{3,4}$ new superconductors, ${ }^{5,6}$ inorganic pigments, ${ }^{7,8}$ and as photocatalyts. ${ }^{9-11}$ Oxynitrides that contain more than two different cations are of significant interest for improvement of these properties. Such compounds have been prepared by the ammonolysis of metal oxide mixtures; however, the variation of compounds is still very limited, partly due to the poor kinetics for the ammonolysis reaction. Ammonolysis of amorphous oxide mixtures prepared through a citrate route improved the problem to develop new oxynitrides such as $\mathrm{RE}_{2} \mathrm{Ta}_{2} \mathrm{O}_{5} \mathrm{~N}_{2}$ pyrochlores $(\mathrm{RE}=\mathrm{Nd} \sim \mathrm{Gd})$, $\operatorname{RETa}(\mathrm{O}, \mathrm{N}, \square)_{4}$ disordered fluorites $(\mathrm{RE}=\mathrm{Dy} \sim \mathrm{Yb})^{12,13}$, wurtzite-type gallium oxynitride compounds doped with various transition metal cations ${ }^{14-19}$, and europium doped aluminum oxynitride. ${ }^{20,21}$ Double metal oxides, especially nanopowders of such, would also contribute to enhance the ammonolysis reaction to obtain new oxynitrides.

$\mathrm{KTiNbO}_{5}$ is a layered compound with interleaved potassium ions between $\left(\mathrm{TiNbO}_{5}\right)^{-}$oxide layers. ${ }^{22}$ It can intercalate n-propyl amine after potassium ion exchange with protons during treatment of $\mathrm{KTiNbO}_{5}$ with $\mathrm{HCl}^{23}$ The interlayer distance expands more than twice during the intercalation process to exfoliate the oxide layers, which results in an exfoliated nanopowder that would be highly reactive for ammonolysis.

In the present study, ammonolysis behavior was studied for the $\mathrm{HTiNbO}_{5}$ (n-propyl amine) intercalation compound and compared with the nitridation reaction of a mixture of $\mathrm{TiO}_{2}$ and $\mathrm{Nb}_{2} \mathrm{O}_{5}$ (2:1 molar ratio). The crystal structure and superconductivity behavior of the nitrided products were also investigated.

$\mathrm{KTiNbO}_{5}$ was prepared by firing a mixture of $\mathrm{K}_{2} \mathrm{CO}_{3}, \mathrm{TiO}_{2}$ and $\mathrm{Nb}_{2} \mathrm{O}_{5}$ in a molar ratio of $1.1: 2: 1$ at $1100{ }^{\circ} \mathrm{C}$ for $20 \mathrm{~h}$. The product (ca. $1 \mathrm{~g}$ ) was reacted at $35^{\circ} \mathrm{C}$ for 1 day with $120 \mathrm{~mL}$ of n-propyl amine after treatment with $\mathrm{HCl}$ to form $\mathrm{HTiNbO}_{5}$, as described in our previous report. ${ }^{23}$ The n-propyl amine intercalated $\mathrm{HTiNbO}_{5}$ was nitrided in the temperature range between 500 and $1200{ }^{\circ} \mathrm{C}$ for $15 \mathrm{~h}$ in an ammonia flow of 50 $\mathrm{mL} / \mathrm{min}$. A mixture of $\mathrm{TiO}_{2}$ and $\mathrm{Nb}_{2} \mathrm{O}_{5}$ with an average grain size of $200 \mathrm{~nm}$ and $300 \mathrm{~nm}$, respectively, in a molar ratio of
2:1 was also nitrided under the same firing conditions as a reference.

Orthorhombic lattice parameters changed from $\mathrm{a}=$ $0.6439, \mathrm{~b}=0.3796, \mathrm{c}=1.838 \mathrm{~nm}$ for $\mathrm{KTiNbO}_{5}$ to $\mathrm{a}=0.6534$, $\mathrm{b}=0.3776, \mathrm{c}=1.661 \mathrm{~nm}$ for $\mathrm{HTiNbO}_{5}$ and then to $\mathrm{a}=0.6428$, $\mathrm{b}=0.3813, \mathrm{c}=3.486 \mathrm{~nm}$ for the intercalated $\mathrm{HTiNbO}_{5}(\mathrm{n}-$ propyl amine). The c-parameter was approximately doubled along the layer stacking direction by n-propyl amine intercalation. ${ }^{23}$ Cleavage of the platy crystals was clearly observed along the plane after n-propyl amine intercalation, as shown in Fig. 1. X-ray fluorescence analysis indicated the molar ratio of $\mathrm{Ti}: \mathrm{Nb}$ had been kept at $1: 1$ after the intercalation reaction.

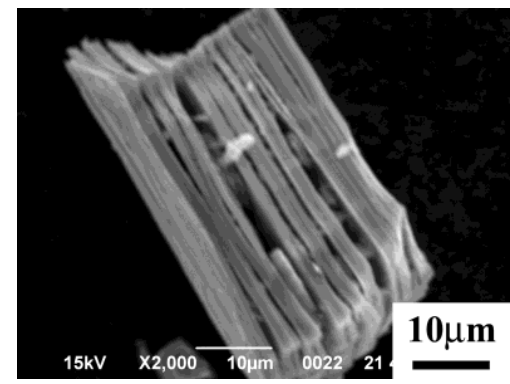

Figure 1. SEM photograph of an n-propyl amine intercalated $\mathrm{HTiNbO}_{5}$ crystal.

Ammonolysis at $800{ }^{\circ} \mathrm{C}$ converted $\mathrm{HTiNbO}_{5}$ (n-propyl amine) to $\left(\mathrm{Ti}_{0.5} \mathrm{Nb}_{0.5}\right) \mathrm{N}$, as depicted in Fig. 2 . The crystallinity of the nitrided product was improved by ammonolysis at $1000{ }^{\circ} \mathrm{C}$. The cubic lattice parameter increased from $\mathrm{a}=$ $0.4283 \mathrm{~nm}$ at $800{ }^{\circ} \mathrm{C}$ to $0.4302 \mathrm{~nm}$ at $1200{ }^{\circ} \mathrm{C}$, which was slightly smaller than the reported value of $0.4328 \mathrm{~nm} .{ }^{24}$ The nitrided product had small amounts of oxygen impurity and cation vacancy in its rock salt lattice as mentioned below. The nitrided product prepared from a mixture of $\mathrm{TiO}_{2}$ and $\mathrm{Nb}_{2} \mathrm{O}_{5}$ under the same conditions was a mixture of isostructural $\left(\mathrm{Ti}_{1-}\right.$ $\left.{ }_{\mathrm{x}} \mathrm{Nb}_{\mathrm{x}}\right) \mathrm{N}$ compounds having two compositions, $\mathrm{x}>0.5$ and $\mathrm{x}<$ 0.5 , due to inhomogeneous reaction. The nitrided products of the intercalation compound at $1200{ }^{\circ} \mathrm{C}$ exhibited superconductivity below $\mathrm{T}_{\mathrm{c}}=15 \mathrm{~K}$ and the volume fraction was $85 \%$. The values of $T_{c}$ and the volume fraction decreased with the decreasing ammonolysis temperature, as summarized in Table 1. The temperature was lower than the reported value of $17.5 \mathrm{~K},{ }^{25}$ probably due to the structural imperfection originated from the intercalated layer structure as described in next section. The oxygen and nitrogen contents were measured with an oxygen/nitrogen analyzer (EMGA-620W, Horiba) using inert gas fusion method. The observed molar ratios of $\mathrm{N} /(\mathrm{O}+\mathrm{N})$ and $(\mathrm{Ti}+\mathrm{Nb}) /(\mathrm{O}+\mathrm{N})$ are shown in Table 1. The nitrogen molar ratio was increased in the total amount of anions with the increasing ammonolysis temperature, however 
a small amount of cation vacancy of $7 \%$ was still present in the rock salt lattice nitrided at $1200^{\circ} \mathrm{C}$.

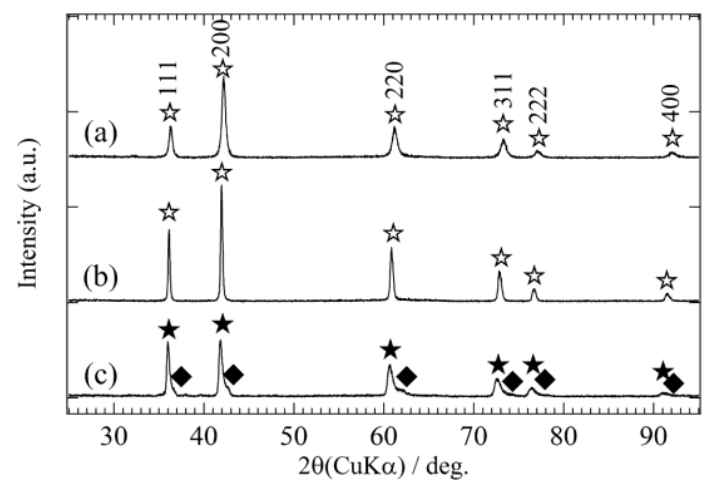

Figure 2. Powder X-ray diffraction patterns for the ammonolysis products from (a) $\mathrm{HTiNbO}_{5}$ (n-propyl amine) at $800^{\circ} \mathrm{C}$, (b) $\mathrm{HTiNbO}_{5}$ (n-propyl amine) at $1000^{\circ} \mathrm{C}$ and (c) a mixture of $\mathrm{TiO}_{2} / \mathrm{Nb}_{2} \mathrm{O}_{5}=2 / 1$ in molar ratio at $1000^{\circ} \mathrm{C}$. Diffraction lines marked with open, filled stars, and crosses were assigned to those of $\left(\mathrm{Ti}_{0.5} \mathrm{Nb}_{0.5}\right) \mathrm{N},\left(\mathrm{Ti}_{1-\mathrm{x}} \mathrm{Nb}_{\mathrm{x}}\right) \mathrm{N}$ with $\mathrm{x}>$ 0.5 and $x<0.5$, respectively.

Table 1. Superconductive characteristics, nitrogen and oxygen content of the nitrided $\mathrm{HTiNbO}_{5}$ (n-propyl amine) at various temperatures.

\begin{tabular}{c|c|c|c|c}
\hline \multirow{2}{*}{$\begin{array}{c}\text { Ammonolysis } \\
\text { temperature } /{ }^{\circ} \mathrm{C}\end{array}$} & \multirow{2}{*}{$\mathrm{T}_{\mathrm{c}} / \mathrm{K}$} & $\begin{array}{c}\text { Volume } \\
\text { fraction/\% }\end{array}$ & $\begin{array}{c}\mathrm{N} / \\
(\mathrm{O}+\mathrm{N})\end{array}$ & $\begin{array}{c}\text { Molar ratio } \\
(\mathrm{O}+\mathrm{N})\end{array}$ \\
\hline 1200 & 15 & 85 & 0.99 & 0.93 \\
\hline 1000 & 15 & 80 & 0.96 & 0.88 \\
\hline 900 & 12 & 55 & 0.91 & 0.86 \\
\hline 800 & 7 & 20 & 0.85 & 1.15 \\
\hline
\end{tabular}

The relative intensity of the $\mathrm{X}$-ray diffraction pattern for the $1000{ }^{\circ} \mathrm{C}$ nitrided product $\left(\mathrm{Ti}_{0.5} \mathrm{Nb}_{0.5}\right) \mathrm{N}$ was not well simulated with the rock-salt type crystal structure by refining the $4 a$ site cation occupancy of $\mathrm{Ti}$ and $\mathrm{Nb}$ in $F m-3 m$ with some amount of vacancies. The relative diffraction intensity should not be affected by the preferred orientation in an isotropic crystal structure such as $F m-3 m$, but by some type of disordering such as an imperfection of long range ordering along the direction in the previous $\left(\mathrm{TiNbO}_{5}\right)^{-}$layer stacking. The radial distribution around $\mathrm{Nb}$ was obtained by Fourier transform of the $\mathrm{Nb} \mathrm{K}$-edge extended X-ray absorption fine structure (EXAFS). The first nearest neighbors for $\mathrm{Nb}-(\mathrm{N}, \mathrm{O})$ appear at $0.17 \mathrm{~nm}$ for the present nitrided products, as well as for the commercially-available $\mathrm{NbN}$, as depicted in Fig. 3. The second nearest neighbor for $\mathrm{Nb}-\mathrm{Nb}$ was observed at 0.27 $\mathrm{nm}$ in $\mathrm{NbN}$ and its intensity was stronger than that for the first nearest $\mathrm{Nb}-\mathrm{N}$, due to the much larger $\mathrm{X}$-ray scattering factor in $\mathrm{Nb}$ than in $\mathrm{N}$, which was very weak for the present nitrided products. The rock-salt type crystal lattice was much easily formed within than across the $\left(\mathrm{TiNbO}_{5}\right)^{-}$layers in the intercalated compound, because of the much shorter contact distance between $\mathrm{TiO}_{2}$ and $\mathrm{Nb}_{2} \mathrm{O}_{5}$ within the layers. The stacking defects lead to the psuedo two dimensional rock-salt type lattice and reduced the radial distribution intensity for the second nearest neighboring $\mathrm{Nb}-(\mathrm{Nb}, \mathrm{Ti})$.

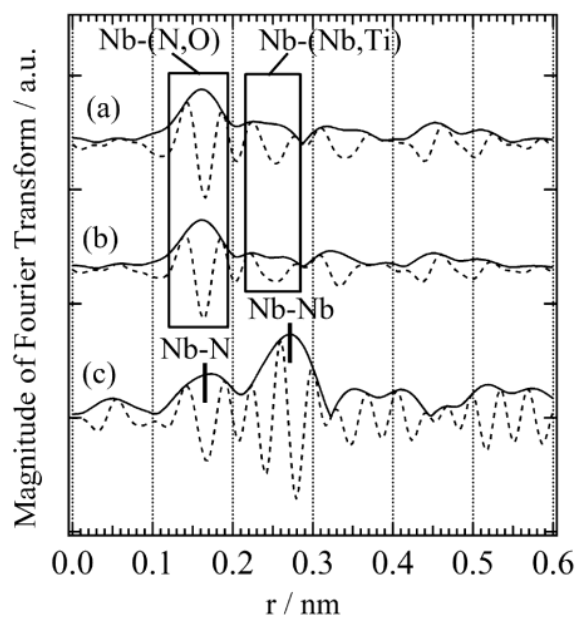

Figure 3. Fourier transformation of EXAFS in X-ray absorption spectra; (a) nitrided $\mathrm{HTiNbO}_{5}$ (n-propyl amine) at $1000{ }^{\circ} \mathrm{C}$, (b) nitrided $\mathrm{HTiNbO}_{5}$ (n-propyl amine) at $800{ }^{\circ} \mathrm{C}$ and (c) $\mathrm{NbN}$ reference, respectively.

In conclusion, superconducting $\left(\mathrm{Ti}_{0.5} \mathrm{Nb}_{0.5}\right) \mathrm{N}$ was prepared by the ammonolysis of the $\mathrm{HTiNbO}_{5}$ (n-propyl amine) intercalation compound at a relatively lower temperature than that for preparation from a mixture of $\mathrm{TiO}_{2}$ and $\mathrm{Nb}_{2} \mathrm{O}_{5}$. The crystal structure was assumed to be a rocksalt type with a large stacking disorder along the stacking direction in the layer structure of the $\mathrm{HTiNbO}_{5}$ starting material.

This research was partly supported by a Grant-in-Aid for Scientific Research (Kakenhi (A) \#21245047) from the Japan Society for the Promotion of Science (JSPS). X-ray absorption experiments were performed under the approval of Proposal No. 2010G135 from the Photon Factory Advisory Committee.

\section{References and Notes}

1 R. -J. Xie, M. Mitomo, K. Uheda, F. F. Xu and Y. Akimune, J. Am Ceram. Soc., 2002, 851229.

2 J. W. H. van Krevel, J. W. T. van Rutten, H. Mandal, H. T. Hintzen and R. Metselaar, J. Solid State Chem., 2002, 165, 19.

3 Y. -I. Kim, P. M. Woodward, K. Z. B. -Kishi and C. W. Tai, Chem Mater., 2004, 16, 1267.

4 Y. Zhang, T. Motohashi, Y. Masubuchi and S. Kikkawa, J. Ceram. Soc. Jpn., 2011, 119, 581.

5 S. Yamamoto, Y. Ohashi, Y. Masubuchi, T. Takeda, T. Motohashi and S. Kikkawa, J. Alloys Compd., 2009, 482, 160.

6 Y. Ohashi, T. Motohashi, Y. Masubuchi and S. Kikkawa, J. Solid State Chem., 2010, 183, 1710.

M. Jansen and H. P. Letschert, Nature, 2000, 404, 980.

F. Tessier and R. Marchand, J. Solid State Chem., 2003, 171, 143.

K. Maeda and K. Domen, J. Phys. Chem. C, 2007, 111, 7851.

10 K. Maeda, H. Hashiguchi, H, Masuda, R. Abe and K. Domen, J. Phys. Chem. C, 2008, 112, 3447.

11 F. Tessier, P. Maillard, F. Chevire, K. Domen and S. Kikkawa, J. Ceram. Soc. Jpn., 2009, 117, 1.

12 P. Maillard, F. Tessier, E. Orhan, F. Chevire and R. Marchand, Chem. Mater., 2005, 17, 152.

13 S. Kikkawa, T. Takeda, A. Yoshiasa, P. Maillard and F. Tessier, Mater. Res. Bull., 2008, 43, 811. 
14 S. Kikkawa, K. Nagasaka, T. Takeda, M. Bailey, T. Sakurai and Y. Miyamoto, J. Solid State Chem., 2007, 180, 1984.

15 S. Kikkawa, S. Ohtaki, T. Takeda, A. Yoshiasa, T. Sakurai and Y. Miyamoto, J. Alloys Compd., 2008, 450, 152.

16 S. Yamamoto, S. Kikkawa, Y. Masubuchi, T. Takeda, H. Wolff, R. Dronskowski and A. Yoshiasa, Solid State Commun., 2008, 147, 41.

17 S. Yamamoto, S. Kikkawa, Y. Masubuchi, T. Takeda, M. Okube, A. Yoshiasa, M. Lumey and R. Dronskowski, Mater. Res. Bull., $\mathbf{2 0 0 9}, 44,1656$

18 A. Miyaake, Y. Masubuchi, T. Takeda, and S. Kikkawa, Mater. Res. Bull., 2010, 45, 505.

19 A. Miyaake, Y. Masubuchi, T. Takeda, T. Motohashi and S. Kikkawa, Dalton Trans., 2010, 39, 6106.

20 S. Kikkawa, H. Hatta and T. Takeda, J. Am. Ceram. Soc., 2008, 91, 924.

21 Y. Masubuchi, T. Hata, T. Motohashi and S. Kikkawa, J. Solid State Chem., 2011, in press, doi: 10.1016/j.jssc.2011.07.035.

22 A. D. Wadsley, Acta Cryst., 1964, 17, 623.

23 S. Kikkawa and M. Koizumi, Physica B, 1981, 105, 234.

24 R. Kieffer, H. Nowotny, P. Ettmayer and G. Dufek, Metall, 1972, 26,701 .

25 N. Pessall, R. E. Gold and H. A. Johansen, J. Phys. Chem. Solids, 1968, 29, 19. 
NOTE The diagram is acceptable in a colored form. Publication of the colored G.A. is free of charge.

For publication, electronic data of the colored G.A. should be submitted. Preferred data format is EPS, PS, CDX, PPT, and TIFF. If the data of your G.A. is "bit-mapped image" data (not "vector data"), note that its print-resolution should be 300 dpi.

Description (if any)
Title
Authors' Names
(Ti,Nstalyzed in a rock salt crystal having many structural defects along the stacking direction of the
intercalation compound.

